\title{
Ações judiciais argentinas em saúde e consequências legais na jurisdição brasileira
}

\author{
Argentina's lawsuits on health e legal consequences in Brazilian \\ jurisdiction
}

\section{Agustín Carignani}

Advogado, Especialista em Direito Sanitário. Pesquisador colaborador no Programa de Direito Sanitário da Fundação Oswaldo Cruz, Brasília, Brasil, e Advogado do Ministério da Saúde de Córdoba, Argentina.

\section{Maria Celia Delduque}

Advogada, Especialista em Direito Sanitário. Pesquisadora Adjunta do Programa de Direito Sanitário da Fundação Oswaldo Cruz, Brasília, Brasil e Professora do Mestrado da Universidade de Brasília, Brasil.

Resumo: $O$ artigo analisa duas ações judiciais promovidas na Argentina, sobre transplante de pulmão em razão de fibrose cística, cuja execução se deu no território brasileiro, dando ensejo a alterações normativas no arcabouço legal dos dois países.

Palavras chaves: Direito à saúde, tutela; transplante, regulamentação; transplante, doador vivo; transplante, pulmão.

Resumen: El artículo analiza dos acciones judiciales interpuestas en Argentina sobre trasplante de pulmón debido a la fibrosis quística, cuya ejecución tuvo lugar en el territorio brasileño, dando lugar a cambios normativos en los marcos jurídicos de los dos países.

Palabras clave: Derecho a la salud, tutela; trasplante, reglamentos; trasplante, donante vivo; trasplante de pulmón.

Abstract: The paper examine two lawsuits promoted in Argentina on lung transplant due to cystic fibrosis, whose enforceability was given in Brazil, giving rise to legislative changes in the legal framework of both countries.

Keywords: Right to health, jurisdictional tutelage; transplantation, regulation; transplantation, living donor; transplantation, lung. 


\section{Introdução}

O presente trabalho analisa aspectos da tutela jurídica do direito à saúde no contexto de duas ações judiciais argentinas, cujos efeitos da sentença se deram em dezembro de 2011 e janeiro de 2012, e as reações dos governos argentino e brasileiro, consubstanciadas na produção de novas normativas sobre transplantes.

$\mathrm{Na}$ Argentina, o direito à saúde tem hierarquia constitucional (Constituição Argentina, artigo 75 inc. 22), pois tal direito foi reconhecido em tratados internacionais e incorporado pelo sistema legal argentino, por serem normas supralegais.

As duas ações judicias tiveram como objetivo a realização de procedimentos cirúrgicos em duas pessoas menores de idade, de nacionalidade argentina, que sofriam de fibrose cística. As sentenças condenavam o Governo argentino ao pagamento de transplantes de pulmão com doadores vivos a serem realizados no Hospital da Santa Casa de Misericórdia, da cidade de Porto Alegre, Rio Grande do Sul, Brasil.

A especificidade dessas ações reside justamente nas sentenças judiciais geradas, que tiveram efeitos, no que tange à executoriedade, no Brasil.

Analisam-se as consequências normativas dessas ações, tendo em vista a subsequente reação dos Poderes Executivos da Argentina e do Brasil às sentenças judiciais.

\subsection{Enunciação dos casos estudados}

Caso 1: Ação judicial ajuizada pela menor S.S.S., representada por seus pais, em face da Administración Provincial del Seguro de Salud (APROSS), Estado Nacional e Estado Provincial, numa Ação de Amparo', ajuizada em 15/11/2011 perante o Juizado da $1^{\circ}$ Instância Civil e Comercial de $5^{\text {a }}$ Nominação da cidade de Córdoba, Província de Córdoba, Argentina $^{2}$, tendo como consequência uma sentença, com data de 24/11/2011, que deu lugar à operação cirúrgica de transplante de pulmão com doador vivo, tratamento recomendado pelo médico da autora face à patologia de

\footnotetext{
${ }_{2}^{1}$ Ação judicial argentina semelhante ao Mandado de Segurança brasileiro.

2 Informação disponível na internet na URL: http://www.diaadia.com.ar/cordoba/trasplante-sofiasanchez-fue-exitoso.
} 
fibroses cística ${ }^{3}$. Dita intervenção cirúrgica, realizada em $07 / 12 / 2011$, foi feita no Hospital da Santa Casa da Misericórdia, de Porto Alegre, Brasil ${ }^{4}$, depositando o governo argentino a soma de 478.500 pesos argentinos, correspondendo a 60.000 dólares americanos, para o hospital, e 90.000 reais, para os médicos ${ }^{5}$.

Caso 2: Ação judicial ajuizada pela menor M.O., representada por seus pais, em face do Estado Nacional, Estado Provincial e Administración Provincial del Seguro de Salud (APROSS), na Província de Córdoba, Argentina, com data de 27/08/20106, perante o Juizado da $1^{\circ}$ Instância Civil e Comercial de $5^{\text {a }}$ Nominação da cidade de Córdoba, Província de Córdoba, Argentina ${ }^{7}$. Dita operação foi realizada em Porto Alegre, Brasil, no Hospital da Santa Casa da Misericórdia ${ }^{8}$, em 18/01/2012, tendo como resultado um transplante de pulmão com doador vivo, depois de ter sido diagnosticada com fibrose cística.

\section{Metodologia}

Trata-se de uma pesquisa descritivo-analítica, com base em estudo de caso, em que se utilizaram técnicas de pesquisa bibliográfica e documental (decisões judiciais).

Os dois casos judiciais estudados são considerados paradigmáticos, pela sua natureza, e tiveram muita repercussão nos meios de comunicação na Argentina. Trata-se de duas acciones de amparo.

As normativas baixadas pelo Ministério da Saúde do Brasil sobre o tema do transplante de estrangeiros, editadas logo após os casos mencionados, foram obtidas nas bases de dados de informação legislativa mantidas na internet por aquele órgão e a legislação argentina sobre transplante de pulmão intervivos, no sítio (www.infoleg.mecon.gov.ar).

\footnotetext{
3 Informação disponível na internet na URL: http://www.clarin.com/ sociedad/trasplante_pumonar_con_donantes_vivos-Sofia_Sanchez-alta_medica_0_614338749.html.

${ }^{4}$ Informação disponível na internet na URL: $\overline{h t t p: / / w w w . c l a r i n . c o m / s a l u d / s o c i a l-d e b e n-c u b r i r-t r a s p l a n t e-~}$ Brasil_0_597540335.html.

5 Informação disponível na internet na URL: http://www.cadena3.com/ post_ampliado.asp?historial=NO\&post=88894.

6 Informação disponível na internet na URL: http://www.clarin.com/salud/Marisol-Maribel-gemelastrasplante-pulmon-amparo-Cordoba_0_324567752.html (Consultado em 19.09.2012). Tradução livre.

7 Informação disponível na internet na URL: http://www.lavoz.com.ar/brasil/fallo-favor-maribel-oviedopara-su-trasplante-brasil.

8 Informação disponível na internet na URL: http://www.diaadia.com.ar/cordoba/maribel-oviedo-seratrasplantada.
} 


\section{Resultados e discussão}

As duas ações foram decididas pela mesma autoridade jurisdicional, uma vez que, na Argentina, especificamente na justiça cordobesa, nos casos de acciones de amparo (mandados de segurança), onde se precisa de uma solução eficaz e rápida da controvérsia legal em razão da natureza do pedido, mais especificamente nas causas onde a saúde está comprometida, aplica-se a competência por conexão das causas judiciais que têm características similares, prevista no artigo 7 inc. 2) da Lei Provincial no 8.465, de 1995 (Argentina, 1995). Isso é, os casos são distribuídos ao juiz que já tenha resolvido causas de características análogas, evitando-se, assim, obter sentenças contraditórias, entendendo-se, também, que esse julgador está em melhor posição e com mais subsídios para dar uma solução mais rápida, adequada e ajustada.

\subsection{O direito à saúde como direito fundamental da pessoa humana}

A Organização Mundial da Saúde entende a saúde como "estado de completo bem-estar físico, mental e social e não meramente a ausência de doença ou enfermidade" ${ }^{\prime 9}$ (OMS, 2012).

Esse conceito de saúde está reconhecido pela Constituição Federal brasileira (art. 196) e também pela Constituição argentina, nos princípios constitucionais dos Tratados e Convênios Internacionais incorporados pelo artigo 75 inc. $22^{10}$. Em ambos os casos, a saúde é reconhecida como direito fundamental da pessoa humana.

Sem dúvida, tem que ser assim, no sentido de que "o direito é feito pelo homem e para o homem, que constitui o valor mais alto de todo ordenamento jurídico" (Tobeñas, 1952, p.6). Os princípios da vida, da dignidade humana e da saúde são os princípios fundamentais de uma sociedade, encontrando, assim, os princípios constitucionais, sua razão e origem no homem (Correa de Andrade, 2008).

Os direitos à vida, à saúde e à integralidade são direitos reconhecidos na Convenção Americana de Direitos Humanos, na Declaração Universal dos Direitos Humanos, na Declaração Americana dos Direitos e Deveres do Homem ${ }^{11}$, no Pacto

\footnotetext{
${ }^{9}$ Conceito de saúde da Organização Mundial da Saúde (OMS) incorporado na Constituição da OMS de 1946.

${ }_{11}^{10}$ Incorporado na Constituição da Nação Argentina na reforma de 1994.

11 O Brasil é reconhecido defensor dos direitos humanos, sendo um dos signatários originais da Declaração Americana dos Direitos e Deveres do Homem.
} 
Internacional dos Direitos Civis e Políticos, bem como na Convenção sobre os Direitos da Criança. O direito à vida está singularmente protegido pela Constituição Argentina no artigo 75 inc. 22, sendo reconhecido nos Tratados e Pactos Internacionais que foram incorporados à Constituição na reforma de 1994.

Nesse sentido, resolveu a Corte Suprema de Justiça Argentina entendendo que o direito à saúde está intimamente relacionado com o direito à vida, sendo esse o primeiro direito da pessoa humana reconhecido e garantido pela Constituição Nacional (Argentina, Juzg. Federal nํ2, 2010).

Na Argentina como no Brasil, as ações judiciais contêm uma breve exposição sobre o direito fundamental à saúde, sua previsão constitucional e sua aplicabilidade direta e imediata. Depois, abordam a solidariedade dos entes federativos ${ }^{12}$ frente ao tema em questão e o objeto da obrigação assistencial de saúde (Barros Gutiérrez Slaibi, 2012).

Em certas ocasiões, as pessoas que utilizam o sistema público de saúde se veem na necessidade iminente de um tratamento que seja de acordo com as suas necessidades, e por distintas razões, sejam políticas ou orçamentárias, o sistema não está preparado para atender a demanda de dita prestação. É justamente nessas situações que os princípios mencionados nos tratados referidos apresentam-se como importantes ferramentas da garantia do direito à saúde.

\subsection{Saúde como dever do Estado}

A incorporação do direito à saúde como direito fundamental da pessoa humana responde a distintas circunstâncias sociais que vinham se produzindo na América Latina. Conforme afirma Aith (2010), no Brasil, a partir da década de 1980, a redemocratização foi importante para a melhoria do sistema de proteção dos direitos humanos e, em especial, a proteção da saúde.

A Constituição brasileira de 1988, da mesma forma que cria o direito de todos à saúde, cria, para o Estado, o dever de garantir saúde por meio de políticas públicas que incluem acesso universal a ações e serviços. Assim a saúde é, ao mesmo tempo, um direito e um dever; de um lado está o Estado e, do outro, os cidadãos. Essa assertiva está na Constituição brasileira no artigo 196 que dispõe:

\footnotetext{
12 Se fala de entes federativos entendendo assim ao Estado Federal, Provincial e Municipal, no caso argentino, e a União, os Estados e os Municípios, no caso brasileiro.
} 
A saúde é direito de todos e dever do Estado, garantido mediante políticas sociais e econômicas que visem à redução do risco de doença e de outros agravos e ao acesso universal e igualitário às ações e serviços para sua promoção, proteção e recuperação. (original sem grifo)

$\mathrm{Na}$ Argentina, os antecedentes da saúde como políticas de governo se encontraram na Constituição de 1949, quando se criou o Ministério da Saúde, mas foi em 1994 que se Ihe outorgou status constitucional, sendo o direito à saúde compreendido como uma espécie do gênero dos direitos sociais.

Até a reforma constitucional de 1994, não houve referências ao direito à saúde no texto constitucional. Apenas então, com a introdução do artigo 42, é que a Constituição Argentina dispôs sobre a proteção da saúde, mas no contexto particular das relações de consumo.

Os consumidores e usuários de bens e serviços têm direito, na relação de consumo, à proteção da sua saúde (...). As autoridades proverão a proteção desses direitos, à educação para o consumo, à defesa da concorrência (...) à qualidade e eficiência dos serviços públicos (...).

A inclusão do art. 75 inc. 22 inaugura, em 1994, o dever do Estado argentino para com a saúde, mediante o que se incorporam os tratados e pactos internacionais já mencionados.

Nos sistemas constitucionais de ambos os países, se prevê o acesso à saúde afiançado pelo Estado e garantido com base em políticas públicas - sociais e econômicas - previstas para tais fins. Contudo, no momento de ter que definir um tratamento médico, uma medicação mais adequada, tendo, por um lado, o direito fundamental da pessoa humana e, pelo outro, as leis que preveem esses tratamentos ou medicamentos "mais adequados" para a patologia dos pacientes, os juízes se encontram na necessidade de priorizar as leis do sistema normativo, fazendo prevalecer umas sobre outras igualmente válidas, sendo justamente esses casos de conflito.

\subsection{A tutela jurídica do direito à saúde e o direito internacional}

No caso das decisões judiciais em análise, os juízes da Província de Córdoba entenderam que o Estado Argentino deve garantir a integridade física, a saúde e a vida das pessoas em base aos princípios já analisados, não podendo, portanto, o sistema público de saúde esquivar-se de dita obrigação. 
É assim que, em sua decisão, o juiz revela ter encontrado um caso de difícil solução

nos termos de Ronald Dworkin, que argumenta que há dois tipos de casos: o difícil e o fácil. Casos difíceis são aqueles em que a solução emerge da literalidade dos textos normativos pré-constituídos e a existência de provas irrefutáveis dos factos. Casos difíceis, por outro lado, são aqueles em que as circunstâncias sugerem várias soluções "diferentes", às vezes, "contraditórias", e a ordenação não é clara em apontar que deve seguir para o caso; ou aqueles em que a resposta foi clara, mas moralmente inaceitável ou contrária com algum valor fundamental. (Sánchez apud Zavaley e Robledo, 2010, p. 125).

Com Zavaley e Robledo (2011 p. 244) entendemos que o holding ${ }^{13}$ dessas ações judiciais refere-se a que o Estado:

deve assegurar a integridade física e o direito à saúde (...) dada à gravidade que é a imagem da doença do autor, significa enfrentar a cobertura total do procedimento a ser realizado no exterior, devido a melhores condições que se apresenta [...].

Tratavam-se, efetivamente de "casos difíceis" porque, até a data das ações judiciais analisadas, o Estado Argentino não tinha previsão legal para procedimentos cirúrgicos de transplante de órgãos com doadores vivos. Com a propositura das ações judiciais de realizar as cirurgias no Brasil e com base nas decisões decorrentes dos tribunais, abriu-se o ensejo de alterar tal legislação proibitiva.

Neste sentido, lembremos, com Delduque e Marques, que:

O Poder Judiciário, em todas as suas instâncias, vem se deparando com um volume cada vez maior de ações judiciais individuais que reivindicam os mais diversos medicamentos, insumos, tratamentos e produtos de saúde em face do Estado, como garantia do direito à saúde constitucionalmente resguardada. (Delduque e Marques, 2009, p. 121)

Daí que o Judiciário está na obrigação de resolver o caso concreto no marco das leis vigentes e, por mais complexas que sejam as questões postas em juízo, deve se pronunciar a respeito, proferindo uma decisão que colocará fim ao processo, pois esse Poder não pode deixar de decidir - o que é sua maior característica: o non liquet. (Delduque; Marques e Ciarlini, 2011).

\footnotetext{
${ }^{13}$ O "Holding" é a resposta para a questão central e o raciocínio seguido pelo Tribunal de Justiça na sua decisão.
} 
Em decorrência, essas decisões tornaram-se paradigmáticas, pois tiveram consequências em outros sistemas para além do jurídico, provocando novas realidades normativas, tanto na Argentina quanto no Brasil.

Como expressa Torronteguy e Ventura (2012, p. 81) o direito à saúde não é só um produto de legislações nacionais, já que também existem importantes textos internacionais que reconhecem o acesso à saúde como direito e que, além disso, existem leis que determinam que se cumpra com o direito estabelecido.

São justamente esses textos normativos de Direito Internacional que justificam as sentenças judiciais argentinas que responderam aos pedidos de tratamentos médicos não compreendidos nas políticas públicas e que provocam despesas de grande porte.

\section{Consequências jurídicas e sanitárias}

No sistema legal argentino, até fevereiro de 2012, não se tinha previsão da realização de transplante de pulmão com doador vivo. Por outra parte, no sistema legal brasileiro, antes de fevereiro de 2012, não existiam regulamentações para as intervenções cirúrgicas feitas no Brasil em estrangeiros não residentes, na hipótese de transplante de pulmão com doador vivo.

Para a apreciação das alterações legislativas ocorridas após as sentenças que estamos estudando, observe-se o seguinte quadro comparativo:

Quadro I - Legislação sobre transplantes de órgãos da Argentina e do Brasil antes e depois de fevereiro de 2012.

\begin{tabular}{|c|l|l|}
\hline País & \multicolumn{1}{|c|}{ Antes } & \multicolumn{1}{c|}{ Depois } \\
\hline Argentina & $\begin{array}{l}\text { O Decreto do Poder Executivo } \\
\text { no 512, de 17/4/1995, não } \\
\text { regulamentava o transplante } \\
\text { de pulmão entre doadores } \\
\text { vivos. }\end{array}$ & $\begin{array}{l}\text { Decreto do Poder Executivo } \\
\text { no 239, publicado em 13/2/2012, } \\
\text { regulamenta o transplante de pulmão } \\
\text { entre doadores vivos e modifica o art. } 14 \\
\text { do Decreto no 512, de 1995. }\end{array}$ \\
\hline Brasil & Sem previsão. & $\begin{array}{l}\text { Portaria do Ministério da Saúde no 201, } \\
\text { de 08/2/2012, que dispõe sobre a } \\
\text { remoção de órgãos, tecidos e partes do } \\
\text { corpo humano vivo para fins de } \\
\text { transplantes no território nacional } \\
\text { envolvendo estrangeiros não residentes } \\
\text { no país. }\end{array}$ \\
\hline
\end{tabular}

Fonte: normativas sobre transplantes disponíveis na internet. 
Enquanto, na Argentina, havia previsão legal sobre o transplante de pulmão, mas restrito a doadores cadavéricos, no Brasil, não havia qualquer regulamentação quanto ao transplante em estrangeiros realizado em território nacional, em vista de uma lista nacional de espera por esse tipo de procedimento cirúrgico.

Após fevereiro de 2012, a Argentina passou a contar com uma legislação autorizativa do transplante intervivos e o Brasil regulamentou esse procedimento em estrangeiros não residentes no país, obrigando sua inclusão na lista oficial de espera por transplante.

\subsection{Situação na Argentina}

Na legislação argentina, se editou o Decreto no 239, de 13/2/2012, por meio do qual se acrescentou o inciso $i$ ao artigo 14 do anexo I do Decreto no 512, de 1995, adicionando o pulmão como órgão passível de extração de doador vivo, e atribuindo ao Instituto Nacional Central Único de Ablação e Implante (INCUCAI) ${ }^{14}$ a competência para determinar os critérios técnicos para a seleção dos doadores e receptores.

O Decreto no 239/2012 traz, como motivos autorizativos do transplante intervivos, a evolução dos conhecimentos médico-científicos e os aprimoramentos tecnológicos da atividade transplantadora.

De fato, os transplantes com doadores vivos tiveram início em 1990, com o Professor Starnes, em Los Angeles, nos Estados Unidos, como um último recurso para pessoas jovens a ponto de morrer, ${ }^{15}$ e o primeiro transplante de lóbulos pulmonares em pacientes com fibrose cística foi realizado no Reino Unido, em julho de 1995, pelo Professor Sir Magdi Yacoub. ${ }^{16}$ O Decreto vem, 17 anos depois, modernizar a técnica-médica e a lei argentinas.

Em verdade, do ponto de vista técnico, não haveria vantagens no transplante com doador vivo frente ao cadavérico, no caso da fibrose cística. "A única diferença é

\footnotetext{
${ }^{14}$ O Instituto Nacional Central Único de Ablação e Implante (INCUCAI) é a entidade que promove, regula, coordena e monitora as atividades de doação e transplante de órgãos, tecidos e células na Argentina. Ele atua nas províncias argentinas com 24 órgãos jurisdicionais da ablação e implante para proporcionar um acesso equitativo e transparente para transplante. Informação disponível na internet na URL: http://www.cfww.org/pub/spanish/cfwnl/4/1118/Trasplante_de_l\%C3\%B3bulos_pulmonares_procedente S de_donantes_vivos_para_pacientes_con_fibrosis_qu\% $\%$ C3\%ADstica.

${ }_{16}$ Informação disponível na internet na URL: http://www.cfww.org/pub/spanish/cfwnl/4/1118/Trasplante_de_l\%C3\%B3bulos_pulmonares_procedente s_de_donantes_vivos_para_pacientes_con_fibrosis_qu\%C3\%ADstica.
} 
nos tempos, por isso é que se avalia [o emprego da estratégia] nos casos de estrita emergência". "O motivo pelo qual não se estendem os transplantes com doadores vivos, no caso do pulmão, é porque os resultados não são melhores do que aqueles obtidos com doadores cadavéricos" (Abud, 2012). Em vista disso, a prática do transplante de pulmão com doador vivo está caindo em desuso em nível mundial, de acordo com os dados reportados pela Sociedade Internacional de Transplante de Coração e Pulmão (ISHLT).

Segundo o informe realizado pelo Comité de Bioética do INCUCAI, é isso que a ISHLT mostra em seu relatório do ano 2009, sendo os resultados do transplante de pulmão com doador vivo inferiores a curto e longo prazo, quando comparados com os transplantes de doadores cadavéricos. Nos últimos três anos, a frequência de transplantes com doadores vivos reduziu-se de maneira importante tanto no registro internacional como no Brasil $^{17}$. Segundo o Comité de Ética do INCUCAI, ${ }^{18}$ "o transplante de pulmão com doadores vivos é uma prática marginal no mundo".

\subsection{Situação no Brasil}

O precedente análogo mais antigo levantado na nossa pesquisa é o Mandado de Segurança n²003.34.00.029960-8, de 2003, que tramitou na Justiça Federal brasileira, impetrado por cidadão argentino em desfavor do Ministério da Saúde brasileiro, na pessoa do Coordenador Geral do Sistema Nacional de Transplantes. Teve liminar deferida e sentença confirmada para inclusão do paciente na lista nacional de transplantes de órgãos daquele Ministério. As decisões, liminar e sentença, são fundamentadas no entendimento dos pactos internacionais de direitos humanos já referidos. ${ }^{19}$

No mesmo precedente, se faz referência à viabilidade da aplicação do Acordo Bilateral Brasil-Argentina aprovado pelo Congresso Nacional por meio do Decreto

\footnotetext{
17 Informação disponível na internet na URL: http://bibliotecadigital.uca.edu.ar/ repositorio/revistas/recomendacion-comite-bioetica-incucai-gemelas.pdf.

18 Informação disponível na internet na URL: http://www.pagina12.com.ar/diario/sociedad/3-1525052010-09-03.html.

${ }^{19}$ Embora incluído na lista de transplante no Brasil, o paciente foi transplantada em seu país de origem em 6/10/2006 - imagina-se que com doador cadavérico, pois ainda não havia sido sancionado o Decreto n 239/2012 - prejudicando a ação judicial no Brasil.
} 
Legislativo n 145, de 2011, publicado no Diário Oficial da União em 3 de junho de $2011^{20}$.

Segundo Lourenzatto,

considerando que, no todo, [o Acordo] não versa sobre direitos humanos, aplica-se em tese a teoria dualista, que condiciona a vigência interna e internacional à promulgação e a publicação do decreto de execução presidencial. Portanto, o Acordo encontra-se em vigência internacional, mas não gerando efeitos no plano interno. Esta posição não é consensual, haja vista, a possiblidade de aplicação do § $1^{\circ}$, artigo $5^{\circ}$, da Constituição Federal, que preconiza que as normas definidoras dos direitos e garantias fundamentais têm aplicação imediata (Lourenzatto, 2012, p. 31-32).

Embora o Acordo não se encontre em plena vigência, caberia discutir sua aplicação aos casos que estamos estudando, já que, levando em conta que ele trata de áreas de fronteiras do Brasil e da Argentina, não teria aplicação aqui, uma vez que as cidades de Córdoba, na província argentina de Córdoba, e Porto Alegre, no estado brasileiro do Rio Grande do Sul, não são cidades fronteiriças. ${ }^{21}$

Diante dos casos estudados, o Ministério da Saúde do Brasil, mediante Portaria $\mathrm{n}^{\circ}$ 201, de 7 de fevereiro de 2012, "considerando a necessidade de regular a remoção de órgãos, tecidos e partes do corpo humano vivo para fins de transplantes no território nacional envolvendo estrangeiros não residentes no país; resolve:" (original sem grifo).

Art. 10 A realização de qualquer procedimento de transplante no território nacional em potencial receptor estrangeiro não residente no país apenas ocorrerá a partir de doador vivo que daquele seja conjugue ou parente consanguíneo até o quarto grau, em linha reta ou colateral.

$\S 5^{\circ}$ A retirada de tecido, órgãos e partes do corpo vivo será precedida da comprovação de comunicação ao Ministério Público.

§ 9ํㅡㄹevá ser incluído no Cadastro Técnico Único todo potencial doador e receptor estrangeiro para fins de transplantes no Brasil.

Art. $2^{\circ}$ A eventual realização de transplantes de órgãos, tecidos, células ou partes do corpo humano em receptores estrangeiros não

\footnotetext{
20 Informação disponível na internet na URL: http://www6.senado.gov.br/ legislacao/DetalhaDocumento.action?id=263650.

${ }^{21}$ Embora seja redundante, 0 art. I estabelece os beneficiários e o âmbito de aplicação: "O presente Acordo se aplica aos nacionais das Partes com domicílio, de acordo com as disposições legais de cada Estado, nas áreas de fronteiras enumeradas no Anexo I, sempre que sejam titulares da carteira de Trânsito Vicinal Fronteiriço, emitida conforme previsto nos artigos seguintes, e somente quando se encontrem domiciliados dentro dos limites previstos neste Acordo". (original sem grifo)
} 
residentes no território nacional por meio de financiamento com recursos do Sistema Único de Saúde (SUS) apenas poderá ocorrer mediante prévia existência de acordos internacionais em base de reciprocidade.

É assim que essa Portaria autoriza o transplante em estrangeiro não residente no país, sob a condição de que o órgão doado seja originário de um parente vivo de até o quarto grau. Há que considerar, ainda, que o doador e o receptor deverão estar inscritos no Cadastro Técnico Único.

Seguindo Lourenzatto,

a questão nodal da Portaria talvez seja o artigo $2^{\circ}$, que preconiza a ocorrência de transplantes a expensas do SUS somente em casos de acordos internacionais que destine a reciprocidade aos brasileiros.

Tendo em vista a inexistência de acordo internacional firmado pelo Brasil, sob as condições especificas de reciprocidade no campo da saúde, é possível depreender que a Portaria fora direcionada à seara privada, ou seja, o estrangeiro não residente somente poderá realizar transplante intervivo no Brasil, utilizando o sistema privado de saúde (Lourenzatto, 2012, p. 43).

\section{Resultados e conclusões}

Por todo o exposto, claro está que os dois casos estudados foram, de fato, paradigmáticos.

Em primeiro lugar porque, sem qualquer previsão legal, duas pessoas se beneficiaram de transplantes de pulmão com técnicas não permitidas na Argentina e sem previsão legal para tal, no Brasil.

Em segundo, pode-se verificar que as sentenças judiciais analisadas não apenas garantiram o direito à vida das autoras, mas, para, além disso, conseguiram provocar mudanças na regulamentação existente sobre o tratamento dos portadores de fibrose cística necessitados de transplante em ambos os países. De um lado, o Brasil passou a ter um regulamento especial para possibilitar o transplante com doador vivo em estrangeiros não residentes; por outro lado, houve a inclusão do transplante intervivos de pulmão na legislação argentina. A edição desses novos regulamentos se fez com apenas cinco dias de diferença entre eles.

Embora não exista documentação comprovando irrefutavelmente a vinculação entre as sentenças judiciais e as novas normas, existem elementos suficientes para presumir uma relação de causa e efeito. 
Por fim, uma última conclusão é relacionada à ideia de que o Poder Judiciário pode e deve atender às necessidades da saúde e da ciência, com a produção de decisões inovadoras que tragam soluções para casos atuais, como o exposto. Isso permite que os demais poderes possam rever seus critérios e permitir a incorporação de novas tecnologias médicas que, embora tendo sido desenvolvida há muitos anos, não estava permitida nem prevista na legislação argentina; e a outra, que regularizou uma situação que, até então, não tinha regulamentação no Brasil.

O Estado, como poder único e indivisível, deve estar sempre a ouvir a sociedade, seja por meio de seus representantes eleitos, seja por meio de ações judiciais coletivas ou individuais, para poder fazer avançar o Direito, especialmente quando questões tão sensíveis como a saúde e a vida estão no centro da discussão.

\section{Referências}

ABUD, Celina. Los trasplantes pulmonares con donantes vivos sólo deben realizarse en casos de urgencia. Informação disponível em URL: http://www.docsalud.com/articulo/1115/los-trasplantes-pulmonares-con-donantesvivos-s\%C3\%B3lo-deben-realizarse-en-casos-de-urgencia(Consultado em 17 jul. 2012).

AITH, Fernando. A saúde como direito de todos e dever do Estado: o papel dos Poderes Executivo, Legislativo e Judiciário na efetivação do Direito à Saúde no Brasil. In: Aith, Fernando. Direito Sanitário, Saúde e Direito um Diálogo Possível. Belo Horizonte: Autentica, 2010. ISBN: 978-85-7526-512-3.

ARGENTINA. BUENOS AIRES. Decreto $n^{\circ}$ 239, de 13 de fevereiro de 2012. Transplante de órgãos e material anatómico humano. Informação disponível na internet na URL: http://www.infoleg.gov.ar/infoleglnternet/anexos/190000194999/194232/norma.htm (Consultado em 8 jun. 2012).

ARGENTINA. BUENOS AIRES. Decreto $n^{\circ}$ 512, de 10 de abril de 1995. Transplante de órgãos e material anatómico humano. Informação disponível na internet na URL: http://www.hcdn.gov.ar/leyes/buscarNormasXNumLey.jsp?id_norma=5103

(Consultado em 8. jun. 2012).

ARGENTINA. Constituição (1994). Constitución de la República Argentina de 22 de agosto de 1994. Santa Fe: Convención Nacional Constituyente, 2009.

ARGENTINA. CORDOBA: Legislatura da Província de Córdoba. Lei provincial no 8.465, de 27 de abril de 1995. Código de Procedimento Civil e Comercial da Província de Córdoba. Informação disponível na URL: http://web2.cba.gov.ar/web/leyes.nsf/85a69a561f9ea43d03257234006a8594/7eda1e8 $1718 f e 0 d d 03257250005953 \mathrm{db}$ ?OpenDocument (Consultado em 8 jun. 2012).

ARGENTINA. CORDOBA: Juzgado Federal nำ2, Dr. Alejandro Sanchez Freites, ação judicial "O, M y otra c/ Estado Nacional" (Expte. N³2- O-10). Resolución No427/2010) data 03.9.2010. Disponível em www.clarin.com/.../Fallocompleto_CLAFIL20100903_0003.doc (Consultado em 10 jul. 2012). 
ARGENTINA. Instituto Nacional Central Único de Ablação e Implante (INCUCAI). Disponível na internet na URL: http://www.incucai.gov.ar/institucional/index.jsp (Consultado em 8 jun. 2012).

BARROS GUTIÉRREZ SLAIBI, Maria Cristina. Direito Fundamental à Saúde - Tutela de Urgência. 2012, p.2. Disponível na internet na URL: http://www.portaltj.ttrij.jus.br/c/document_library/get_file?uuid=11c201f6-5bf6-4e44b4d8-137441e3d826\&groupld=10136 (C̄onsultado em 16 jul. 2012).

BRASIL. Acordo entre a República Federativa do Brasil e a República Argentina sobre Localidades Fronteiriças Vinculadas. 2011. Informação disponível na internet na

URL:

http://www6.senado.gov.br/diarios/BuscaDiario?tipDiario=1\&datDiario=05/04/2011\&pa ginaDireta $=9357$ (Consultado em 20 nov. 2012).

BRASIL. Constituição (1988). Constituição da República Federativa do Brasil : texto constitucional promulgado em 5 de outubro de 1988. Brasília : Senado Federal, Subsecretaria de Edições Técnicas, 2011. ISBN: 978-85-7018-345-5.

BRASIL. Convenção Americana de Direitos Humanos. Aprovada na Conferencia especializada Interamericana sobre Direitos Humanos. Ratificada pelo Brasil em 25, de setembro de 1992. Informação disponível na internet na URL: http://www.pge.sp.gov.br/centrodeestudos/bibliotecavirtual/instrumentos/sanjose.htm (Consultado em 6 jun. 2012).

BRASIL. Convenção sobre os Direitos da Criança. Adotada pela Resolução n.. 44/25 da Assembleia Geral das Nações Unidas, de 20 de novembro de 1989. Aprovado por Decreto Legislativo oㅡ 28, de 14 de setembro de 1990. Informação disponível na internet na URL: http://www.planalto.gov.br/ccivil_03/decreto/1990-1994/D99710.htm (Consultado em 6 jun. 2012).

BRASIL. Declaração Americana dos Direitos e Deveres do Homem. Aprovada na IX Conferência Internacional realizada em Bogotá em abril de 1948. Informação disponível na internet na URL: http://www.viajus.com.br/viajus.php?pagina=artigos\&id=3913 (Consultado em 6 jun. 2012).

BRASIL. Declaração Universal dos Direitos Humanos. Aprovada na Assembleia Geral da Organização das Nações Unidas (ONU) em 10 de dezembro de 1948. Diário Oficial [da] República Federativa do Brasil, de 9 de março de 1978, mediante aviso do Ministério dos Negócios Estrangeiros. Informação disponível na internet na URL: http://www.gddc.pt/direitos-humanos/textos-internacionais-dh/tidhuniversais/cidhdudh.html (Consultado em 6 de jun. 2012).

BRASIL. Pacto Internacional dos Direitos Civis e Políticos. Adotado pela XXI Sessão da Assembleia Geral das Nações Unidas de 16 de dezembro de 1996. Aprovado no Congresso Nacional por meio do Decreto Legislativo n. 226 de 12 de dezembro de 1991 e entrou em vigor 24 de abril de 1992. Informação disponível na internet na URL: http://portal.mj.gov.br/sedh/ct/legis_intern/pacto_dir_politicos.htm (Consultado em 6 jun. 2012).

BRASIL. Ministério da Saúde. Portaria n.ำ 201, de 07.2.2012.Dispõe sobra a remoção de órgãos, tecidos e partes do corpo humano vivo para fins do transplante. Informação disponível na internet na URL: http://bvsms.saude.gov.br/bvs/saudelegis/gm/2012/prt0201_07_02_2012.html (Consultado em 06.6.2012). 
CLERICI, Rodolfo Ariza. O Direito a Saúde na Corte Suprema de Justiça da Nação. Disponível na internet na URL: http://www.escr-net.org/usr_doc/Clerici_El_Derecho_a_la_Salud_en_la_Corte_Suprema.html\#_ftn18 (Consultado em 18 jul. 2012).

CORRÊA DE ANDRADE, André Gustavo. O principio fundamental da Dignidade Humana e sua Concretização Judicial. Disponível na internet na URL: http://www.portaltj.tjrj.jus.br/c/document_library/get_file?uuid=5005d7e7-eb21-4fbbbc4d-12affde2dbbe\&groupld=10136 (Consultado em 10 jul. 2012).

DELDUQUE, Maria Célia; MARQUES, Silvia Badim. O Direito Social à Saúde deve ser garantido por políticas públicas e decisões Judiciais. In: DELDUQUE, Maria Célia (Org.). Temas Atuais de Direito Sanitário. Brasília: CEAD/FUB, 2009. ISBN: 978-857804-039-0.

DELDUQUE, Maria Célia; MARQUES, Silvia Badim; CIARLINI, Álvaro. Judicialização das Políticas de Saúde no Brasil. MIMEO. 2011.

LOURENZATTO, Paulo Cesar. Acesso de Estrangeiro Não Residente Ao Sistema Único de Saúde: Realização de transplantes em estrangeiro não residente. Monografia apresentada ao Programa de Pós-Graduação Lato Sensu em Saúde Coletiva da Fundação Oswaldo Cruz, Brasília. 2012.

OMS. Constituição da Organização Mundial da Saúde. Informação disponível na internet na URL: http://www.who.int/suggestions/faq/es/index.html> (Consultado em 20 nov. 2012).

SÁNCHEZ FERNÁNDEZ apud ZAVALEY, Nicolás Rodolfo; ROBLEDO Federico. Aspectos novedosos de la protección de la salud y la vida: A propósito del caso "... y otra c/ IOMA y otra s/amparo. In: Ortega, José Emilio/Director. Práctica Jurídica de la Salud Pública II. Córdoba: Ministerio de Salud, 2010, p. 125. ISBN: 978-950-840-0161.

TOBEÑAS, José Castan. Los Derechos de la Personalidad. Madrid: Instituto Editorial Reus, 1952.

TORRONTEGUY, Marco Aurélio A.; VENTURA, Deisy de F. El Derecho a la Salud Construido Internacionalmente. In: DELDUQUE, Maria Célia [et al.]. El Derecho desde la Calle: Introducción Crítica al Derecho a la Salud. Brasília: CEAD/UnB. 2012. ISBN: 978-85-7804-050-5.

ZAVALEY, Nicolás Rodolfo e ROBLEDO, Federico. Aspectos novedosos de la protección de la salud y la vida: A propósito del caso "... y otra c/ IOMA y otra s/amparo. In: Ortega, José Emilio/Director. Práctica Jurídica de la Salud Pública II. Córdoba: Ministerio de Salud, 2011, pág. 244. ISBN: 978-950-840-016-1. 